\title{
ANÁLISE MORFOLÓGICA DO BAIXO CURSO DO RIO CUBATÃO, EM JOINVILLE (SC), NO PERÍODO ENTRE 1938 E 2015: IMPACTO DE BARRAGEM NA MORFODINÂMICA FLUVIAL
}

\author{
Ricardo Michael Pinheiro Silveira \\ Instituto Federal do Paraná (Campus Curitiba) \\ ricardomichaelps@gmail.com \\ Fabiano Antonio de Oliveira \\ Universidade Federal do Paraná \\ foliveira@ufpr.br \\ Gisele Neuman \\ Universidade Federal do Paraná \\ giseleneuman@gmail.com
}

\begin{abstract}
RESUMO
O presente trabalho objetivou analisar o impacto ocasionado na morfologia fluvial pela construção de uma barragem e de um canal retificado (de derivação) no baixo curso do rio Cubatão, localizado no nordeste do estado de Santa Catarina. A análise multitemporal se deu a partir fotografias aéreas e imagens de satélite dos anos de 1938, 1953, 1966, 1996 e 2010 e 2015. Foram delimitados os canais de drenagem de cada ano, seguido do cálculo da sinuosidade e mapeamento dos meandros e barras existentes. Por fim, foram modelados dois cenários do índice de potência do escoamento: um considerando o leito natural e outro apenas o canal de derivação. Como decorrência da construção da barragem e do canal retificado que dividiu o fluxo do rio Cubatão na década de 1950, os resultados expuseram as alterações morfológicas e morfodinâmicas do rio, denotando o aumento da sinuosidade $(4,7 \%)$, a queda progressiva da área ocupada pelo leito vazante $(44 \%)$ e o decréscimo de $78 \%$ da área ocupada por barras. Reforça-se que houve um destacado aumento da sinuosidade do rio entre 1953 e 1966. Próximo à foz, inversamente, a sinuosidade diminuiu em $2 \%$ e a área do leito vazante, de modo destacado, aumentou em $16 \%$.
\end{abstract}

Palavras-chave: Análise multitemporal. Índice de sinuosidade. Meandros. Barras.

\section{MORPHOLOGICAL ANALYSIS OF THE LOW COURSE OF CUBATÃO RIVER IN JOINVILLE (SC), IN THE PERIOD BETWEEN 1938 AND 2015: IMPACT OF BARRAGE IN FLUVIAL MORPHODYNAMICS}

\begin{abstract}
The objective of this work was to analyze the impact of fluvial morphology on the construction of a dam and the derivation channel in the lower course of the Cubatão River, located in northeastern Santa Catarina state. The multitemporal analysis was based on aerial photographs and satellite images from the years 1938, 1953, 1966, 1996, 2010 and 2015. The drainage channels of each year were delineated, followed by the calculation of their sinuosity and mapping of the meanders and bars. Finally, two scenarios of stream power index were modeled: one considering the natural bed and the other just the derivation channel. The construction of the dam and the derivation channel that divided the flow of the Cubatão River in the 1950s, the results exposed the morphological and morphodynamic alterations on the river, with an increase in sinuosity of $4.7 \%$ in the segment, occupied by the riverbed $(44 \%)$ and the decrease of $78 \%$ of the area occupied by bars. It is emphasized that there was a marked increase in the sinuosity of the river between 1953 and 1966. Next to the mouth, inversely, the sinuosity decreased by $2 \%$ and the area of the ebb bed, prominently, increased by $16 \%$.
\end{abstract}

Keywords: Multitemporal analysis. Sinuosity index. Meanders. Fluvial bars. 


\section{INTRODUÇÃO}

No sistema hidrológico, a morfologia fluvial é caracterizada pela sensibilidade frente às variações do contexto ambiental mais abrangente da bacia hidrográfica - seja por fatores evolutivos de ordem majoritariamente natural ou por fatores antrópicos que induzem a aceleram processos morfodinâmicos e, assim, provocam rápidas alterações morfológicas.

As modificações na geometria de canais fluviais, em áreas urbanas, vêm ocasionando desajustes na estabilidade relativa dos canais, podendo levar décadas para que se adequem à nova configuração morfológica (VIEIRA e CUNHA, 2001). Para Winterbottom (2000), em muitas instâncias a resposta fluvial às intervenções humanas é muito mais rápida e mais intensa do que as respostas às influências naturais.

Segundo Surian e Rinaldi (2003), as alterações humanas têm sido avaliadas como um fator-chave de ajustes e intervenções de canais a partir de canalizações, construções de barragens, atividades de mineração, controle de enchentes e mudanças no uso e cobertura da terra, que afetam tanto no fluxo quanto na produção de sedimentos.

A dinâmica do escoamento, no que se refere à perspectiva geomorfológica, ganha significância na atuação exercida pela água sobre os sedimentos do leito fluvial, no transporte de sedimentos, nos mecanismos deposicionais e na esculturação da topografia do leito (CHRISTOFOLETTI, 1981).

Dessa forma, a geometria dos meandros varia com o regime de fluxo e a natureza dos sedimentos, tanto do canal quanto da planície de inundação, sendo este um dos aspectos mais discutidos da geomorfologia fluvial (HOOKE, 2007; LORENZO et al., 2015). O entrelaçamento das ações erosivas e deposicionais, no tempo e no espaço, produz complexos de formas topográficas que surgem como respostas a ambientes de sedimentação em escala de grandeza maior (CHRISTOFOLETTI, 1981).

Para Hooke (2003), os meandros dos rios são objetos de análise por suas feições notáveis, sua relação com a evolução histórica do canal, seu dinamismo e pelas consequências práticas do seu movimento. Os meandros abandonados, por sua vez, são considerados como o estágio final de desenvolvimento por migração lateral de um arco de meandro, mesmo em condições de equilíbrio, onde não há mudanças significativas de sinuosidade geral (HOOKE, 2007).

Charlton (2008) cita que nas últimas décadas do século XX a gestão ambiental incorporou a necessidade de compreender a evolução, comportamento, dinâmica e mudanças dos rios, sendo que os geomorfólogos têm papel fundamental na avaliação das feições fluviais com enfoque na sensibilidade às mudanças no tempo e no espaço. E o sistema fluvial, como sistema aberto quanto ao equilíbrio dinâmico, é dependente da variável de geometria do canal (SALA e INBAR, 1992).

As medições de erosão quantificam o material removido da face exposta de uma margem do rio e são relatadas como uma distância linear por intervalo de tempo — por exemplo, metro por ano. A migração do canal mede o movimento resultante da mudança de localização do rio devido aos efeitos combinados de erosão e deposição (ROWLAND et al., 2016). Lewin (1977) considerou dois tipos de mudanças nos canais de drenagem: i) autogênicas, que são inerentes ao regime natural do rio e abarcam as variações da sinuosidade associadas à migração lateral; ii) alogênicas, que são controladas por mudanças externas, como o clima e as atividades humanas.

Dentre os trabalhos recentes que abordam a temática da geomorfologia fluvial sob perspectiva têmporoespacial, com o mapeamento da evolução histórica de canais fluviais, destacam-se publicações de Scorpio et al. (2015), que teve como enfoque a análise multitemporal de um rio localizado no sul da Itália, em ambiente SIG, no período de 1880 a 2010; Rhoads et al. (2016), que propuseram analisar as mudanças históricas, desde 1820, induzidas por atividades humanas numa rede de drenagem em Illinois, EUA; Mossa (2016), que analisou a variação na geometria de um rio da Louisiana, EUA, de 1880 a 2015, enfatizando o fluxo e os sedimentos.

Lorenzo et al. (2015) utilizaram fotografias aéreas e mapas históricos para reconstruir fases de meandrização de um rio na Espanha desde o século XVIII, calculando comprimento do talvegue, comprimento de onda, raio de curvatura, amplitude, largura e índice de sinuosidade. Em todos os trabalhos se evidencia a importância do reconhecimento da dinâmica pretérita para compreender os processos atuais e sinalizar perspectivas futuras.

$\begin{array}{lllll}\text { Caminhos de Geografia } & \text { Uberlândia-MG } & \text { v. } 21, \text { n. } 76 & \text { Ago/2020 } & \text { p. 01-15 Página } 2\end{array}$


Com a evolução do processamento de dados espaciais em ambiente informatizado e da disponibilidade crescente de produtos derivados do Sensoriamento Remoto, destacam-se métodos automatizados para a análise da evolução fluvial, tais como: Rowland et al. (2016), que propuseram um algoritmo que quantifica as taxas de erosão e acreção a partir de máscaras binárias de imagens de satélite adquiridas em dois períodos distintos; Schwenk et al. (2017) que quantificaram as variações do rio Ucayali, no Peru, com máscaras anuais derivadas de imagens Landsat e introduziram um conjunto de métodos para mapear e mensurar as mudanças de largura, localização, taxas de migração, acreção e erosão e as características têmporo-espaciais do rio pelo software MATLAB. Monegaglia et al. (2018), com aplicação no rio Xingu (Bacia Amazônica), que desenvolveram um método automatizado para a avaliação morfodinâmica multitemporal de rios meandrantes e anastomosados (identificando o canal principal em bifurcações) tendo como base as imagens Landsat.

Em termos gerais, as medições das margens dos rios, ao longo do tempo, podem avaliar as mudanças laterais dos canais e as taxas de erosão (CUNHA, 1996). Nesse contexto, o presente trabalho tem como objetivo principal avaliar o impacto na morfologia do rio Cubatão do Norte, ou somente rio Cubatão como localmente conhecido, ocasionado pela construção de uma barragem e um canal retificado de derivação na década de 1950.

Conforme Pereira (2005), na década de 1950 o Departamento Nacional de Obras de Saneamento (DNOS) construiu uma barragem de derivação próxima à BR-101 e um canal extravasador, retificado e com extensão de $12 \mathrm{~km}$. A barragem tinha como objetivo dividir uma vazão máxima estimada de $400 \mathrm{~m} 3 / \mathrm{s}$ entre o leito original do rio Cubatão e o novo canal, suportando até $75 \%$ da vazão da bacia.

O trabalho se apoia na interpretação de fotografias aéreas do acervo da Prefeitura Municipal de Joinville e de imagens de satélite recentes para reconstruir os canais fluviais nos anos de 1938, 1953, 1966, 1996, 2010 e 2015, destacando as mudanças na geometria do canal e também das principais feições fluviais. Todos os procedimentos operacionais quantitativos foram realizados em ambiente de Sistemas de Informações Geográficas (SIG) com técnicas de geoprocessamento.

\section{Caracterização da área de estudo}

A bacia do rio Cubatão, com área total de $492 \mathrm{~km}^{2}$, localiza-se na região nordeste do Estado de Santa Catarina, abrangendo parcialmente os municípios de Garuva (porção norte) e Joinville (porção sul). Suas nascentes encontram-se na Serra Queimada, com aproximadamente 1180 metros de altitude, e sua foz situa-se no estuário da baía da Babitonga (GONÇALVES et al., 2006).

Em aspectos geomorfológicos regionais, conforme Oliveira (2006) e Haak et al. (2010), a bacia do rio Cubatão compreende, de oeste para leste, o Planalto Atlântico, as escarpas da Serra do Mar e a Planície Costeira. Num mapa geomorfológico produzido na escala 1:65.000, Oliveira e Vieira (2009) classificaram o relevo da área com unidades escarpadas (dividas entre as vertentes de maior declividade dos topos da Serra do Mar e as rampas no terço médio das vertentes) e planas, incluindo as planícies fluviais e planície marinha, além dos morros costeiros que testemunham o reverso erosivo da Serra.

A complexidade da área é marcada pela presença da Baía da Babitonga, do centro urbano-industrial mais desenvolvido do estado de Santa Catarina, Joinville, assim como pela localização de importantes áreas de rizicultura e pela presença significativa de florestas subtropicais bem preservadas nas adjacências.

Destaca-se que devido à disponibilidade restrita de cobertura de material cartográfico, a área analisada compreende apenas o baixo curso do rio Cubatão (figura 1), no ambiente de planície costeira, desde a barragem até a foz. Pelo leito natural a extensão do segmento é de 27,6 quilômetros; pelo canal de derivação, a extensão é de 12 quilômetros. A extensão total do rio é de 88 quilômetros. 
Figura 1 - Localização da área de estudo.

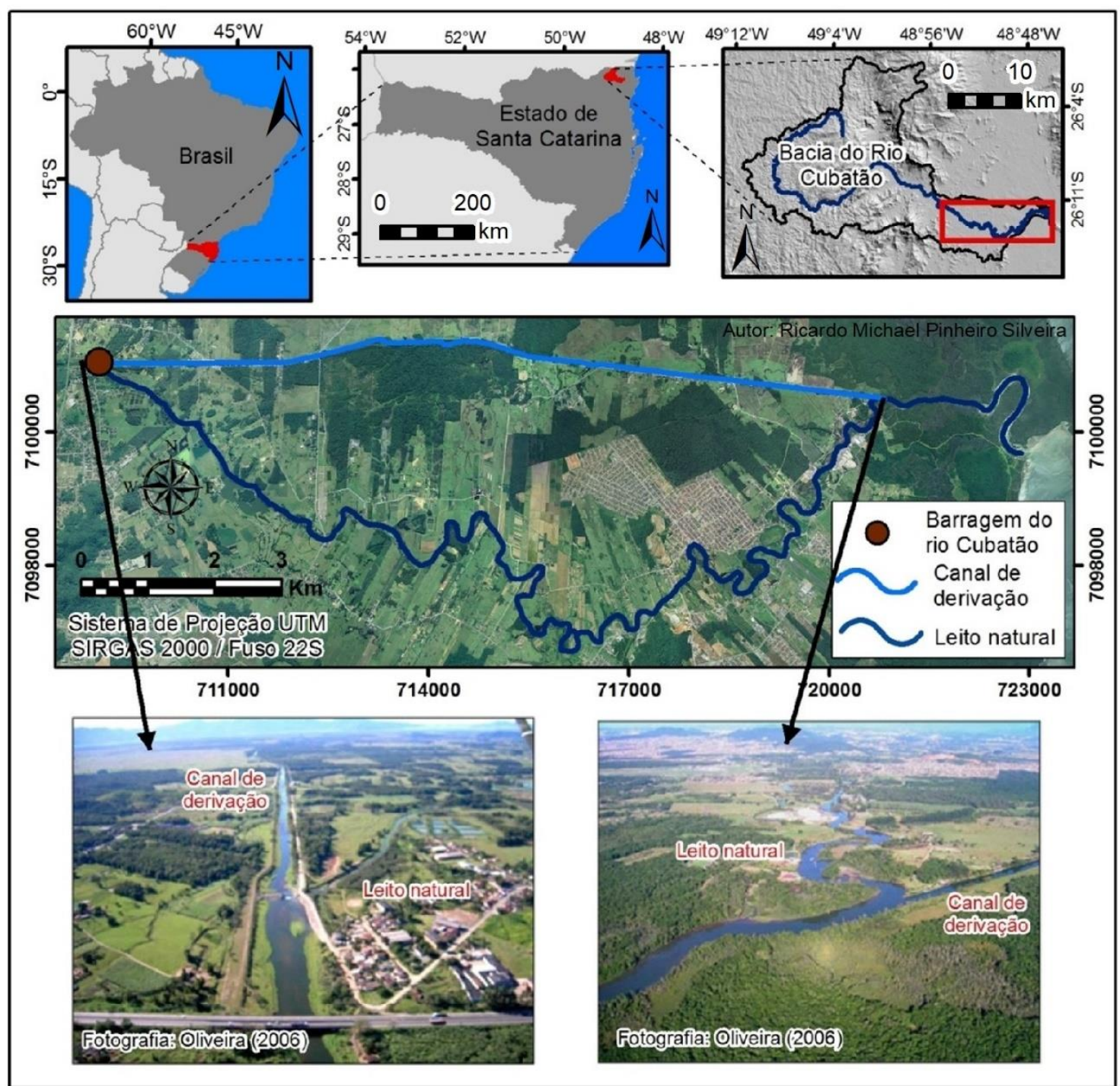

\section{MATERIAIS E MÉTODOS}

A execução deste trabalho se iniciou pela obtenção, georreferenciamento e mosaicagem de fotografias aéreas que contemplam a área de estudo desde o período antecedente à construção da barragem no rio Cubatão. Todos os procedimentos operacionais em ambiente de Sistemas de Informações Geográficas (SIG) foram realizados pelo software ArcGIS 10.1®.

As fotografias aéreas escolhidas, disponibilizadas pela Prefeitura Municipal de Joinville no portal SIMGeo (Sistema de Informações Municipais Georreferenciadas), compreendem o seguinte recorte temporal: 1938 (escala aproximada de voo: 1:20.000), 1953 (escala: 1:12.000), 1966 (escala: 1:8.000), 1996 (escala: 1:6.000) e 2010 (escala: 1:5.000). Além das fotografias aéreas, para o ano de 2015 foi utilizada a imagem WorldView2, com resolução espacial de 50 centímetros, capturada dia 4 de junho, disponibilizada pela DigitalGlobe. Devido às variações de escala das bases para a delimitação das feições fluviais, adotou-se como referência a escala mais generalizada, de 1:20.000.

Sequencialmente foram mapeados os leitos de drenagem de cada ano analisado, objetivando o cálculo da área de estudo e, a partir da linha central do canal, também o índice de sinuosidade do rio. De modo auxiliar, a fim de ilustrar a evolução geomorfológica do rio e destacar pontos a serem observados em campo, todos os meandros abandonados passíveis de identificação nas fotografias aéreas também foram mapeados. 
O cálculo do índice de sinuosidade (IS) do rio seguiu o método de Mansikkaniemi (1970), que considera a relação entre a distância da foz do rio e a nascente mais distante em linha reta e o comprimento do rio principal no formato vetorial (equação 1):

$$
I S=\frac{100(L-L r)}{L}
$$

onde $L$ é o comprimento do rio principal e $L r$ é o comprimento, em linha reta, do exutório até a nascente mais distante. As cinco classes do índice de sinuosidade, indicando atribuições qualitativas, são apresentadas pelo quadro 1.

Quadro 1 - Classes do índice de sinuosidade conforme Mansikkaniemi (1970).

\begin{tabular}{|c|c|c|}
\hline Classe & Descrição & Limites (\%) \\
\hline \hline I & Muito reto & $<20$ \\
\hline II & Reto & 20 a 29 \\
\hline III & Divagante & 40 a 39,9 49,95 \\
\hline IV & Sinuoso & $>50$ \\
\hline V & Muito sinuoso & 40 \\
\hline
\end{tabular}

Fonte: Marcuzzo et al. (2012).

Com a finalidade de analisar a interferência da obra de engenharia na morfodinâmica fluvial, dois segmentos foram distinguidos: a) desde a barragem até o encontro com o canal de derivação, seguindo o leito natural; b) desde o encontro entre leito natural e o canal de derivação até a foz.

Ressalta-se que para o primeiro segmento, devido à cobertura irregular das fotografias aéreas, tanto o índice de sinuosidade quanto o cálculo de área do leito de drenagem foram calculados tendo como referência a cobertura do ano de 1953, cuja extensão contempla a cobertura de todos os anos posteriores analisados. Para o ano de 1938 apenas o segundo segmento foi contemplado em totalidade pelas fotografias aéreas disponíveis.

Como material de apoio foram utilizados: i) dados históricos do Banco de Dados Meteorológicos para Ensino e Pesquisa do Instituto Nacional de Meteorologia (INMET), adotando a estação oㅜ 83844, de Paranaguá/PR, por ser a mais próxima da área de estudo $(80 \mathrm{~km})$ e também por dispor uma série histórica completa para o período analisado; b) dados meteorológicos históricos de estações localizadas dentro da bacia do rio Cubatão, levantados por Silveira (2008).

Por fim, foi realizada uma simulação do Índice de Potência do Escoamento (IPE) considerando dois cenários: i) um modelo que contemplou apenas o leito natural do rio, simulando uma situação pretérita à construção da barragem; ii) um modelo que levou em conta apenas o canal de derivação, simulando uma perspectiva futura da configuração fluvial. Após a obtenção dos IPEs, os dois modelos foram subtraídos para a verificação das áreas de maior variação morfodinâmica.

O IPE (denominado originalmente como Stream Power Index) é um atributo geomorfométrico secundário calculado a partir de um Modelo Digital do Terreno (MDT). Os MDTs utilizados foram interpolados pelo método Topogrid (HUTCHINSON, 1989), no software ArcGIS 10.1®, com célula de 20x20 metros, a partir de dados vetoriais planialtimétricos (pontos cotados, curvas de nível e hidrografia), na escala 1:50.000, disponibilizados pela Mapoteca Topográfica Digital de Santa Catarina (IBGE/Epagri). Considerou-se como recorte espacial a bacia hidrográfica do rio Cubatão em sua extensão total.

O método Topogrid possui a vantagem de derivar MDTs com consistência hidrológica. Assim, para a modelização das duas simulações, foram produzidos dois MDTs: para o modelo do leito natural, o canal de derivação foi excluído do processo de interpolação; inversamente, para o modelo do canal de derivação não 
foi considerado o segmento vetorial correspondente ao leito natural. Os pontos cotados e curvas de nível não foram alterados em ambos os casos.

O IPE, dessa forma, foi obtido pela multiplicação de dois atributos geomorfométricos primários (ou seja, calculados diretamente a partir do MDT): a área de contribuição $\left(A_{c}\right)$ e a tangente da declividade $(\tan \beta)$, conforme equação 2 .

$$
I P E=A_{c} \cdot \tan \beta
$$

A área de contribuição foi quantificada pelo método proposto por Tarboton (1997), com o algoritmo $D$-Infinito. Nesse método, primeiramente é determinado o ângulo de direção do fluxo como a direção mais íngreme considerando as oito facetas triangulares formadas em uma janela $3 \times 3$ células. Após a indicação das direções, o fluxo acumulado é quantificado pela soma das células à montante, ou seja, pela contribuição acumulada do entorno mais elevado. Finalmente, a área de contribuição é obtida pela multiplicação da área de cada célula do MDT (neste caso, 400 metros quadrados) pelo valor do fluxo acumulado.

\section{RESULTADOS E DISCUSSÕES}

\section{A morfologia do baixo curso do rio Cubatão entre 1938 e 2015}

Os resultados obtidos pelo cálculo do índice de sinuosidade e área estimada do leito de drenagem, apresentados pela figura 2, evidenciam duas características fundamentais do rio sob perspectiva espacial e temporal após a construção da barragem: a) houve um destacado aumento da sinuosidade do rio entre 1953-1966, período que contempla a instalação da obra, sendo observado um aumento gradativo, porém menor, nas décadas seguintes até os dias atuais; b) houve uma diminuição progressiva da área ocupada pelo leito natural, cuja queda tem alterado a dinâmica de sedimentação/deposição e, em decorrência, as feições fluviais e consequentemente afetando a própria sinuosidade do rio.

A influência direta do canal de derivação foi evidenciada pela análise setorizada do rio. No primeiro segmento, que compreende o leito natural desde a barragem até o encontro com o canal de derivação, a sinuosidade aumentou $4,7 \%$ após a efetivação da obra. Conforme classificação empregada, o baixo curso do rio passou de divagante, em 1953, para sinuoso, de 1966 em diante. Um exemplo desse efeito é representado pela figura 3 , com destaque para as erosões marginais nos dois meandros utilizados como exemplo que ocasionaram uma mudança de aproximadamente 60 metros no canal entre 1953 e 2015. De modo comparativo pode-se prognosticar que, mantendo a taxa de erosão em condições similares às das últimas décadas, num período de 70 anos (figura 3A) e 120 anos (figura 3B) os meandros em destaque podem ficar abandonados.

Já no segundo segmento, que contempla o encontro entre o leito natural e o canal de derivação até a foz, os resultados indicam uma tendência à inversão nos valores do índice sinuosidade, que diminuiu $2 \%$. Quando ocorre a divisão do fluxo a água tende a seguir com predominância no trecho retificado, deixando o leito natural com menor vazão. Na área de confluência, por sua vez, a vazão do canal de derivação é somada. Com maior energia, a sinuosidade diminuiu e a área aumentou, cujos resultados são perceptíveis - apesar de ser um segmento com menos de 4 quilômetros de extensão. A figura 4 ilustra a evolução morfológica de um meandro próximo à foz do rio Cubatão no período de 1938 a 2015, evidenciando essas mudanças citadas. 
Análise morfológica do baixo curso do rio Cubatão, em Joinville (SC), no período entre 1938 e 2015: impacto de barragem na morfodinâmica fluvial
Ricardo Michael Pinheiro Silveira

Fabiano Antonio de Oliveira Gisele Neuman

Figura 2 - Resultados do cálculo de Índice de Sinuosidade e valores das áreas da calha do rio para os anos analisados.

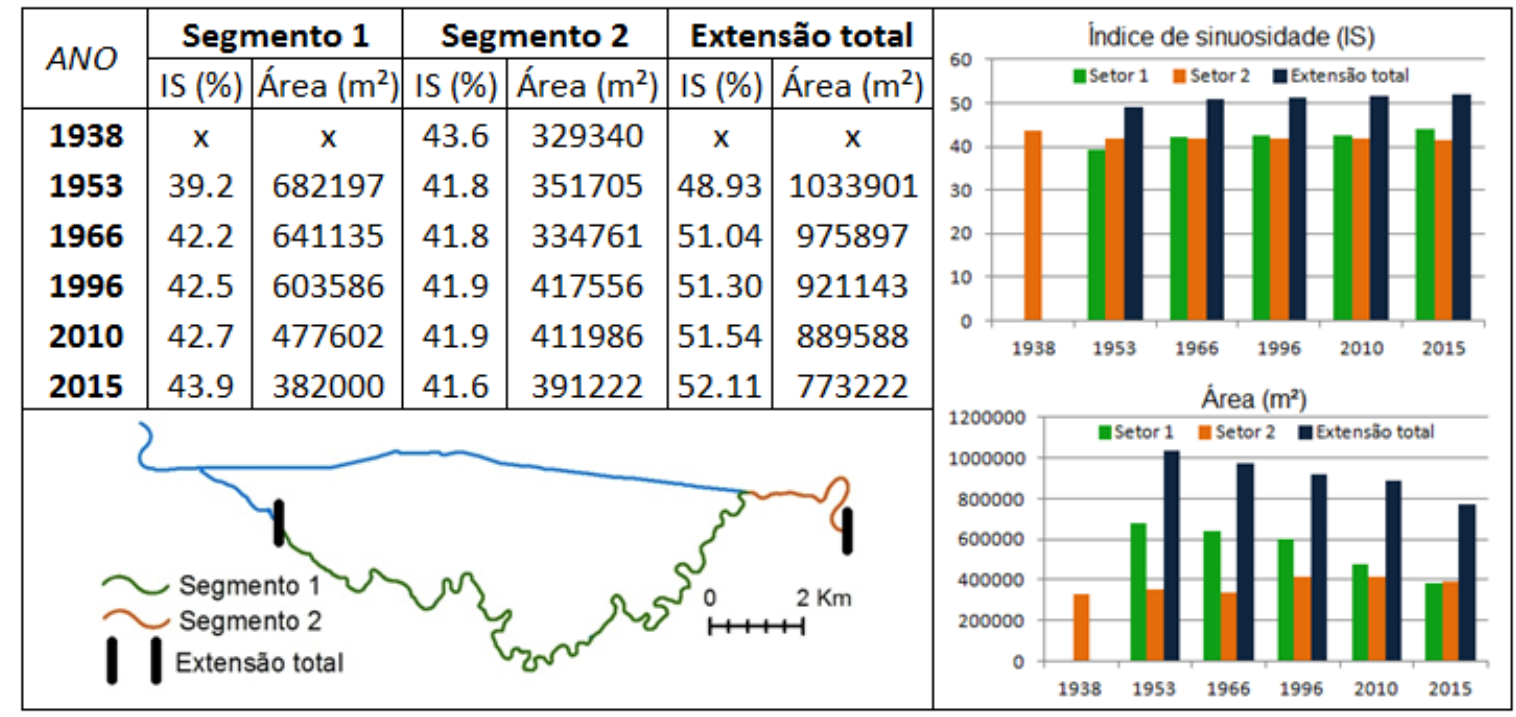

Figura 3 - Exemplos de variações no leito natural do rio Cubatão.

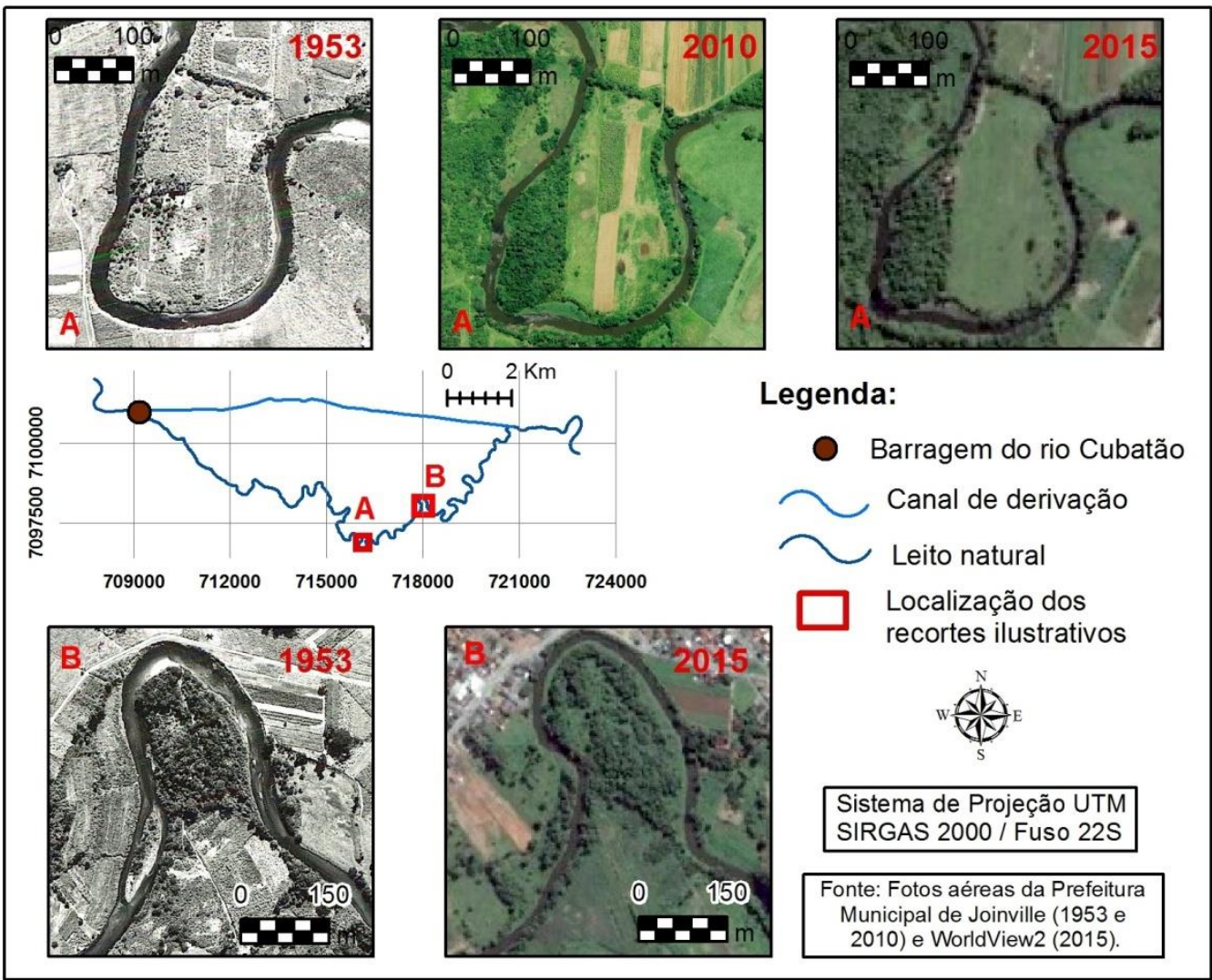

Quanto à estimativa de área, de 1953 a 2015 o leito natural do rio (extensão total analisada) apresentou decréscimo de 25,3\%. Na análise individualizada, o segmento 1 teve redução de $44 \%$ e o segmento 2 , inversamente, aumento de $16 \%$. Nesse sentido, a estimativa de área apresentou resultados que deixam mais evidentes as mudanças provocadas pelo canal de derivação. A redução de área, como ilustra a figura 5, foi gradativa durante todo o período analisado. 
Análise morfológica do baixo curso do rio Cubatão, em Joinville (SC), no período entre 1938 e 2015: impacto de barragem na morfodinâmica fluvial
Ricardo Michael Pinheiro Silveira

Fabiano Antonio de Oliveira Gisele Neuman

Figura 4 - Exemplo da evolução morfológica de um meandro próximo à foz do rio Cubatão.

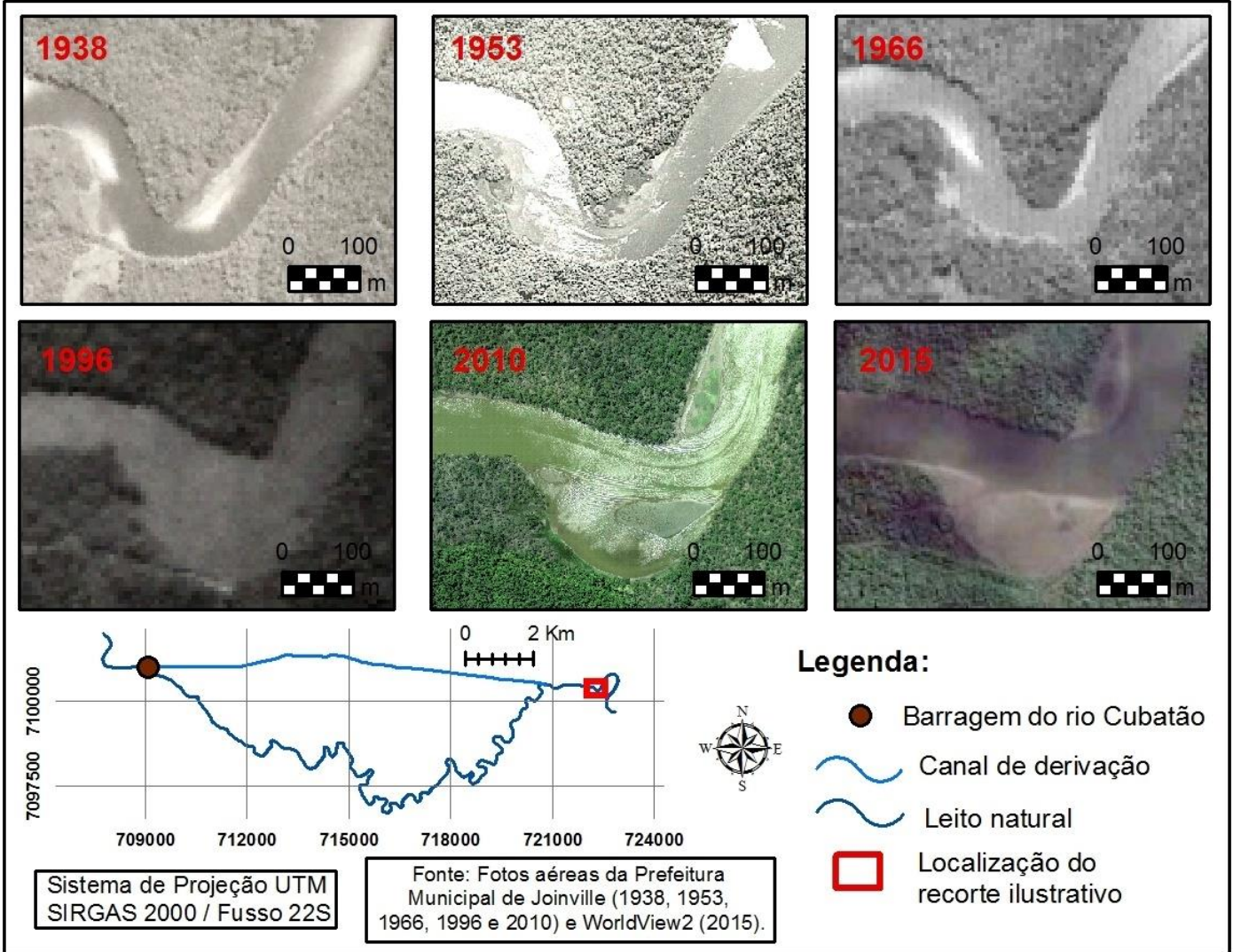

Figura 5 - Exemplo da redução de área da calha do rio no leito natural de 1953 a 2015.
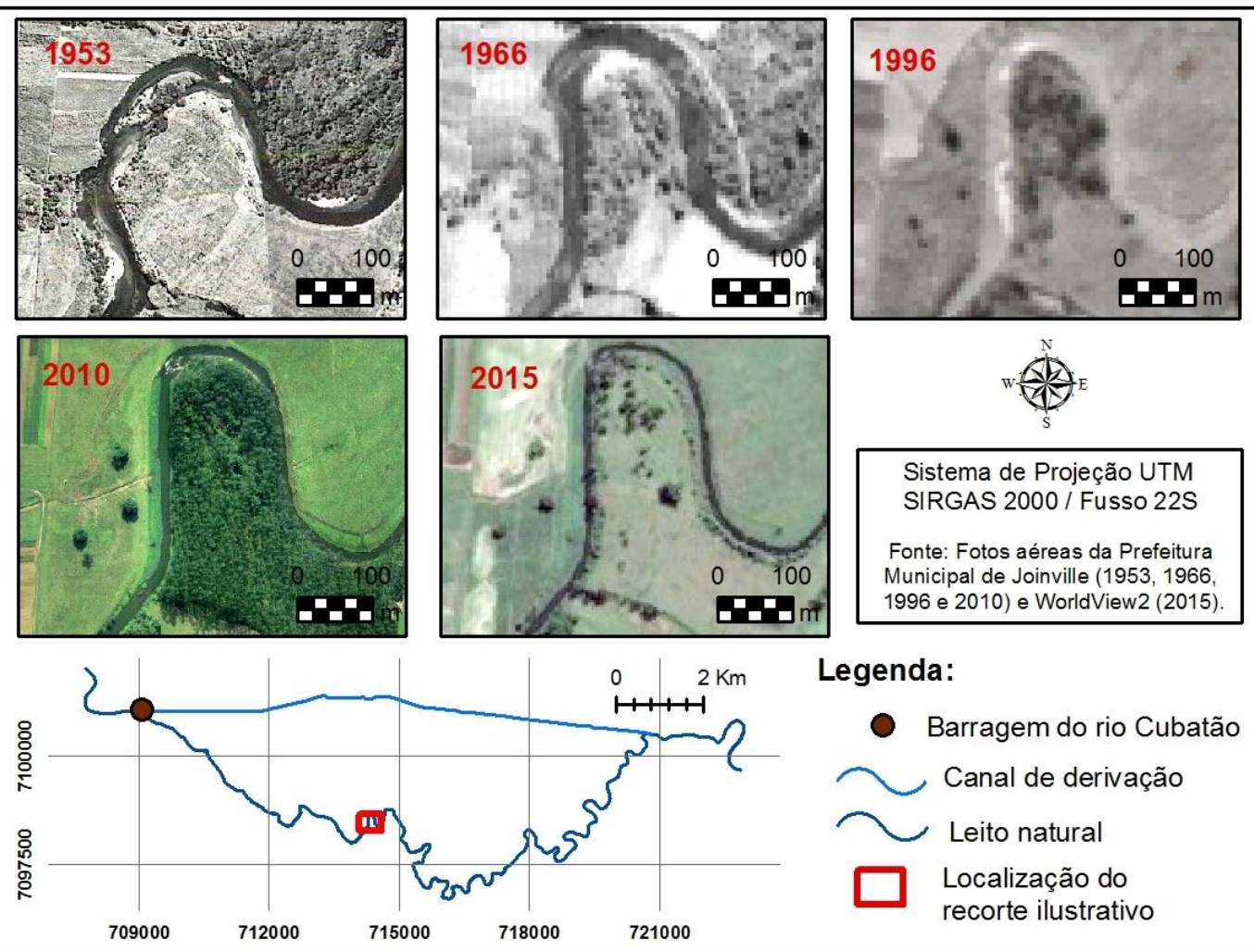

Legenda:

- Barragem do rio Cubatão

Canal de derivação

Leito natural

Localização do

recorte ilustrativo 
A fim de verificar a possibilidade de eventos climáticos episódicos terem interferido no nível e consequentemente na área dos leitos de drenagem para cada ano, os resultados das médias anuais de precipitação pluviométrica levantados foram: 1848mm (1938); 1726mm (1953); 2101mm (1966); 2461 (1996); 2973mm (2010); 2744mm (2015), sendo que a média histórica da estação de Paranaguá (PR) é de 2003mm. Embora estas informações sejam generalizadas, a análise histórica mostra que a precipitação pluviométrica recente é maior do que em meados do século passado. Dessa forma, ainda que de modo preliminar, exclui-se a variável climática como principal responsável para a diminuição de 25,3\% de área do leito natural do rio Cubatão, já que o período atual apresenta chuvas acima da média. A relação histórica, portanto, é inversamente proporcional.

\section{Feições fluviais e indicativos morfodinâmicos do rio Cubatão}

A interpretação visual das fotografias aéreas resultou no mapeamento de 28 meandros abandonados nas adjacências do segmento analisado do rio Cubatão. Considerando que desde barragem até a foz, pelo leito natural, a extensão do rio atualmente é de 27,6 quilômetros, em média a cada quase 1 quilômetro um meandro abandonado foi identificado. Salienta-se que, com exceção da área próxima à barragem que foi aterrada durante a obra e sobrepôs as feições pretéritas, os meandros encontram-se distribuídos de forma regular, sem predomínio em determinado setor, como aponta a figura 6.

Figura 6 - Mapeamento dos meandros abandonados identificados.

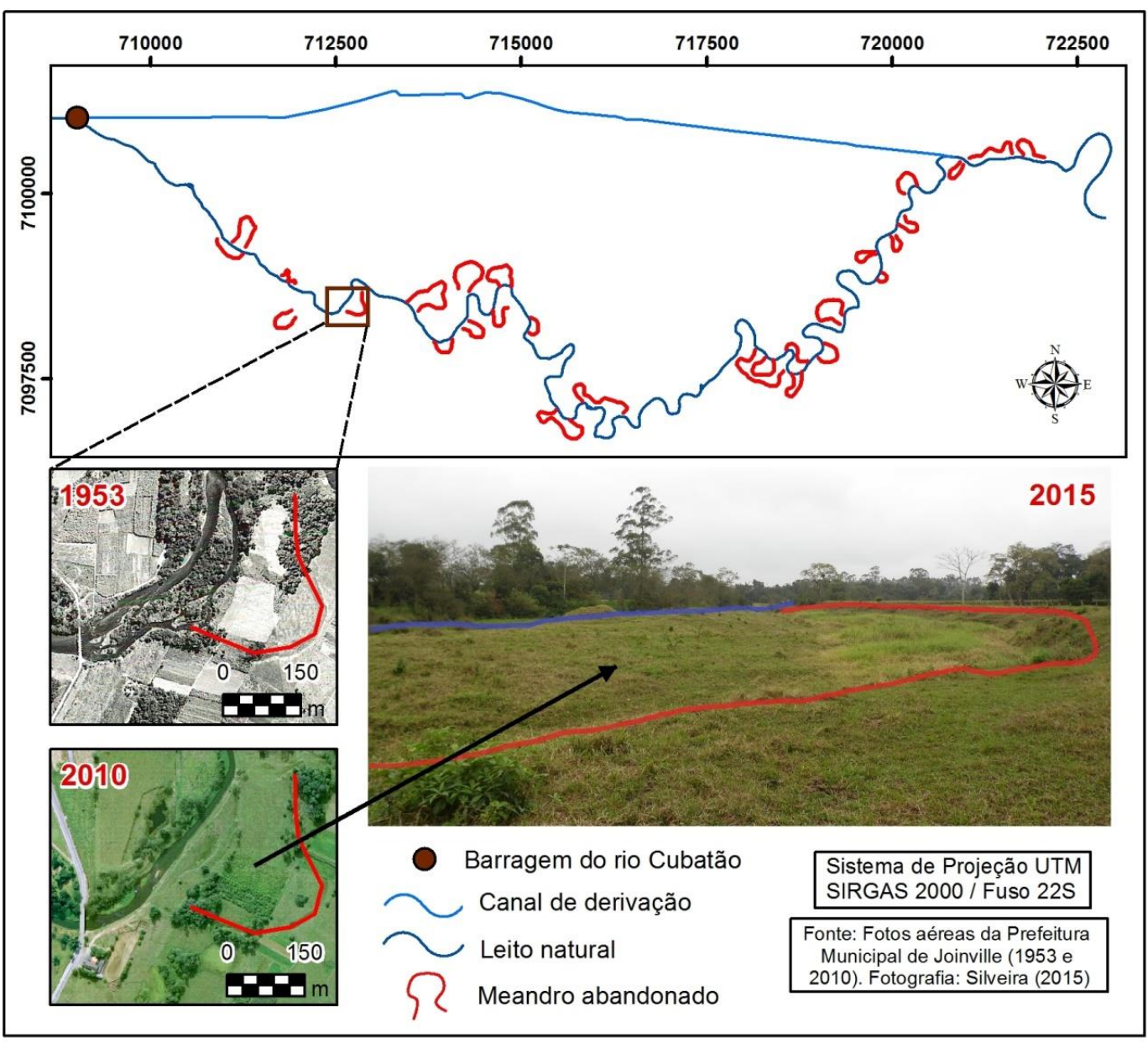

No somatório foram mapeados 20,5 quilômetros (lineares) dessas feições fluviais na área, sendo a extensão média dos meandros abandonados de 735 metros cada. Para fins comparativos, a extensão atual do leito natural é de quase 28 quilômetros. Reforça-se que o número de meandros abandonados deve ser ainda maior, pois apenas aqueles bem destacados nas imagens foram considerados. Atualmente, com a ocupação cada vez mais efetiva no entorno do rio, torna-se cada vez mais difícil mapear essas feições. 
Esses resultados destacam, inicialmente, os efeitos da dinâmica fluvial pretérita na morfologia do rio e denotam o padrão meandrante do canal que, em períodos anteriores, apresentou maior sinuosidade. Com o avanço da urbanização a norte de Joinville, ocupando a planície do rio Cubatão, essas feições fluviais sobressalientes na paisagem ganharam novos usos: alguns meandros foram aterrados e outros transformados em lagos em propriedades privadas, entretanto a maioria, preservados da intervenção direta, restituem-se naturalmente com vegetação em fase inicial/intermediária de sucessão e formações herbáceas e arbustivas de influência fluvial.

Se, por um lado, a atual configuração do rio indica uma tendência ao aumento da sinuosidade (menor energia no leito natural), por outro, o elevado número de meandros abandonados mapeados pode ser um indicativo de que a tendência anterior à construção da barragem era de diminuição (maior energia).

Junto aos meandros, as barras são as feições fluviais que apresentaram as maiores mudanças durante 0 período analisado. As barras de pontal, associadas ao processo de erosão nas margens côncavas e deposição nas margens convexas, se adaptaram conforme as alterações na morfologia fluvial. Já as barras longitudinais e transversais apresentaram significativa redução no leito natural. Em aspectos quantitativos, em 1953 haviam 15 barras ao longo do leito natural com área superior a 100m². Em 2015, apenas 9 barras com essas características foram mapeadas. O tamanho médio das barras calculado para o ano de 1953 foi de $1364 \mathrm{~m}^{2}$, enquanto para 2015 as barras apresentaram área média de apenas $306 \mathrm{~m}^{2}$.

A partir da nova configuração de energia do rio, as barras se mostraram sensíveis às mudanças nos setores analisados. Exemplo disso é apresentado pela figura 7, com o desaparecimento de uma barra longitudinal de 200 metros em função da alteração da vazão do leito natural (a figura 3B representa efeito semelhante), e pela figura 5, com a formação de uma barra de pontal de 120 metros próxima à foz.

Figura 7 - Exemplo de subtração de barra longitudinal durante o período analisado.

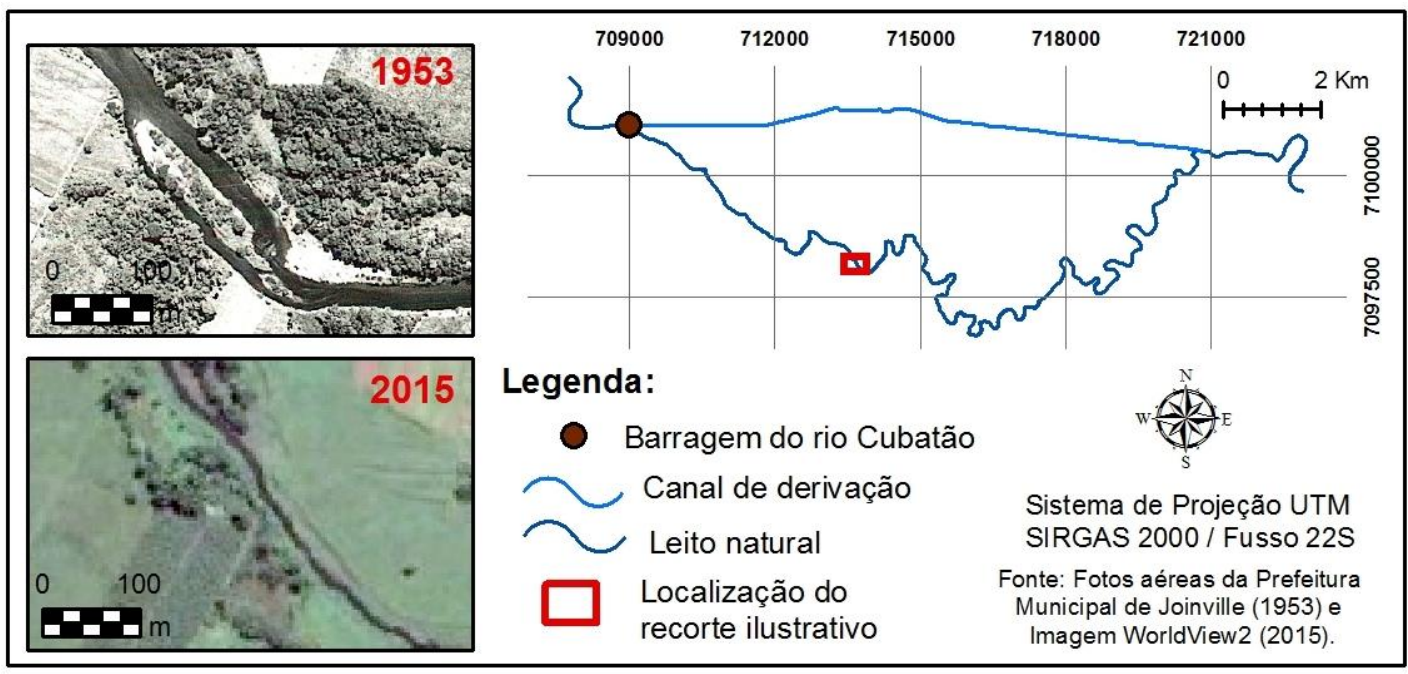

Como destacado pela figura 6, na imagem de 1953 observa-se a presença de um braço do rio, no entorno de uma grande barra, com formação de uma ilha principal e duas outras menores que desaparecem em 2010. Isso também pode ser relacionado com a questão de energia do rio.

De modo geral, a análise das principais feições fluviais assinala as rápidas transformações ocasionadas pela construção da barragem e pelo canal de derivação, de modo complementar e em decorrência da variação da sinuosidade e área do leito de vazante. Embora os rios apresentem ativa morfodinâmica, passíveis de modificações num curto período de tempo, essa análise multitemporal permite distinguir qual é a predominância de fatores naturais e de influência antrópica na configuração morfológica atual e também de prognosticar, ainda que de modo preliminar, problemas associados ao uso e ocupação do solo. 


\section{Modelagem do Índice de Potência do Escoamento (IPE)}

O resultados obtidos pelas simulações do IPE com o leito natural e do IPE com o canal de derivação evidenciaram cenários condizentes com a evolução geomorfológica hipotetizada. Como demonstrado pelo perfil longitudinal disposto na figura 8, a barragem do rio encontra-se na transição do terço médio (de grande potencial erosivo, com quebras mais abruptas que o próprio terço superior) para o terço inferior, na cota dos 30 metros de altitude.

Figura 8 - Perfil longitudinal do rio Cubatão a partir de dados altimétricos do MDT.

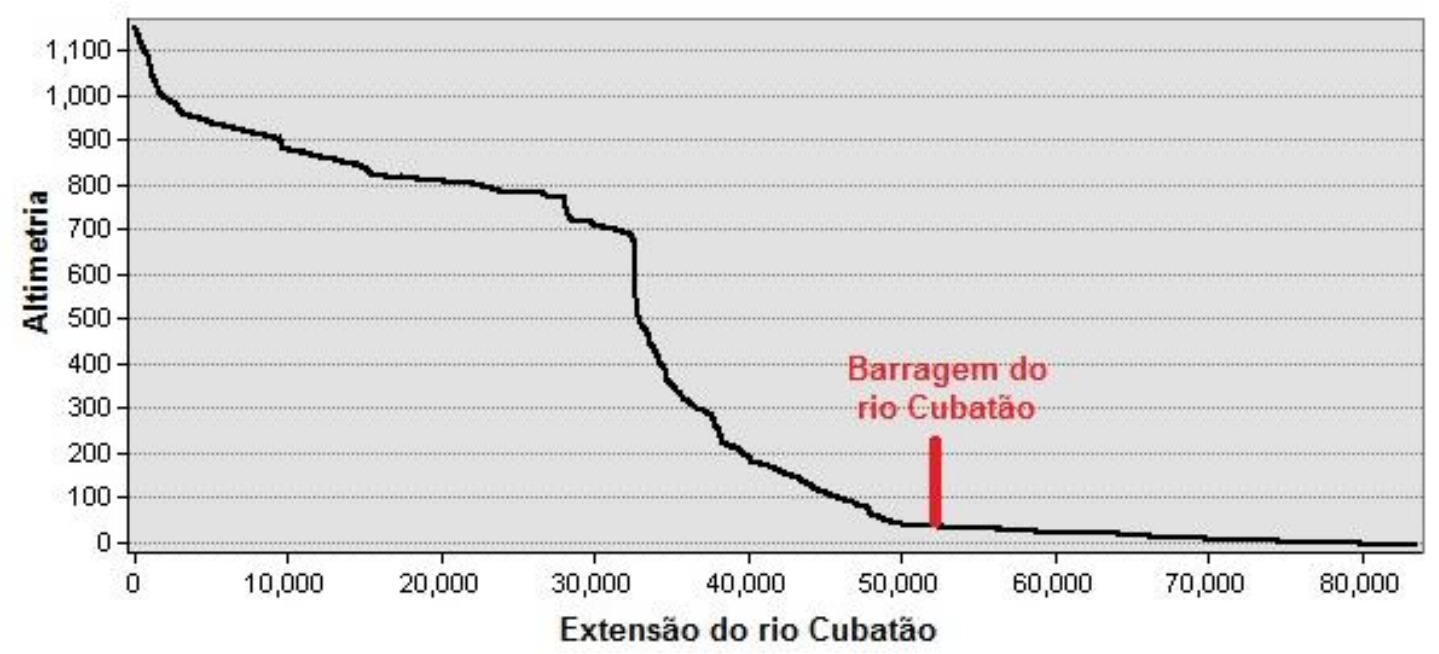

Devido à proximidade entre as áreas fontes de sedimentos dos maciços granítico-gnáissicos da Serra do Mar e a barragem - além do desnível de quase 1200 metros e do efeito orográfico das porções elevadas e topos das montanhas, que marcam os divisores da bacia -, o transporte exercido pelos corpos hídricos do material erodido é ativo e intenso, caracterizando um ambiente bastante instável.

Inicialmente, quanto aos valores de área de contribuição na foz atual do rio Cubatão, o MDT com o traçado original do rio indicou o valor de $14,84 \mathrm{~km}^{2}$. Considerando apenas o modelo do canal de derivação, esse valor cai para $11,68 \mathrm{~km}^{2}$. Isso pode ser explicado pelo padrão de drenagem da bacia em cada simulação. Num cenário futuro com o desaparecimento do segmento original, os atuais tributários do leito natural comporiam uma sub-bacia que dividiria o fluxo para uma porção mais a sul da foz atual. Essa área de contribuição seria correspondente aos $3,16 \mathrm{~km}^{2}$ de divergência na área de contribuição entre as duas simulações.

Como consequência, o Índice de Potência do Escoamento (IPE) apresentou características distintas nos casos modelados, como ilustrado pela Figura 9. Ao subtraí-los, a quantificação das diferenças dos modelos expôs as áreas da bacia de maior variação na dinâmica erosiva considerando os dois cenários. Ainda que a supressão do leito original seja um caso hipotético, já que a vazão na barragem é controlada, a modelagem se faz importante para a compreensão da morfodinâmica tendo como referência uma modificação fluvial induzida. 
Figura 9 - Simulações do Índice de Potência do Escoamento (IPE).

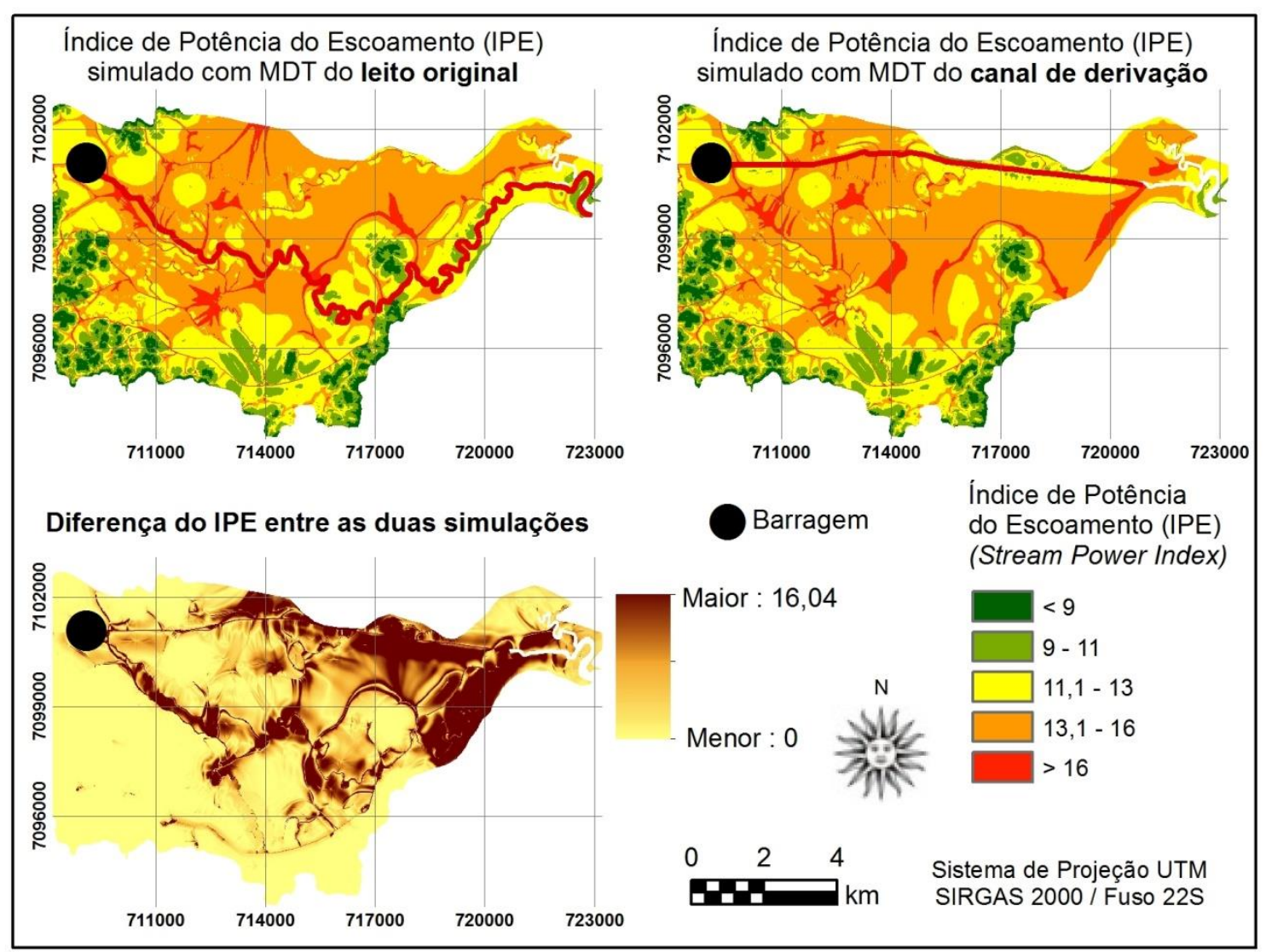

Quanto mais próximo da foz, mais significativas foram as diferenças no potencial de escoamento - fosse uma porção de relevo mais dissecado e os valores seriam mais díspares, já que o IPE considera a declividade como parte do cálculo. Esse resultado corrobora as observações de campo e a análise multitemporal das fotografias aéreas. As áreas que registraram as principais alterações diretas em função da construção da barragem, conforme exemplificado ao longo do trabalho, condizem com as porções em destaque na modelagem.

\section{Impactos associados às mudanças morfológicas e morfodinâmicas}

Os resultados apresentados expõem problemáticas que vinculam a geomorfologia fluvial como subsídio para o planejamento territorial em aspectos multitemporais e multiescalares. A redução de quase metade da área ocupada pelo leito natural de vazante em seis décadas e as alterações morfológicas e de padrões do canal reforçam tais argumentações.

No âmbito multitemporal, com os resultados obtidos, é possível questionar os efeitos das obras de engenharia. Embora a curto prazo a construção do canal de derivação tenha visado amenizar o problema recorrente das inundações para a população residente nas adjacências do leito natural, tal fenômeno é uma condição natural - eis o leito maior (ou excepcional) que configura a planície de inundação do rio Cubatão e que conta com ocupação crescente. A longo prazo, entretanto, os impactos resultantes da obra, hoje implícitos à percepção, podem se tornar grandes problemas socioambientais.

Como consequência direta, o assoreamento da baía da Babitonga se sobressai como um dos principais pontos de atenção. Conforme estimativa de Oliveira (2006), o rio Cubatão é responsável pelo lançamento de 5931 toneladas/ano de sedimentos em suspensão na baía da Babitonga. Com a alteração fluvial justamente no terço inferior do rio, caracterizado pela deposição desses sedimentos, a retificação pode ocasionar um gradativo malefício inclusive de ordem econômica. Os sedimentos, ao aportarem no Canal do Palmital, são retrabalhados pela influência das marés. O porto de São Francisco localiza-se a aproximadamente 15 quilômetros (margeando a costa) da foz do rio Cubatão. 
No âmbito multiescalar, destaca-se a abrangência espacial dos impactos. Ainda que em nível regional as consequências sejam estimadas e projetadas, no âmbito local as mudanças são facilmente observáveis. No aspecto fundiário, por exemplo, é interessante notar que devido à gradativa redução da área ocupada pelo leito de vazante nas últimas décadas, muitas propriedades localizadas no entorno do leito natural tiveram ganho de terreno. Por outro lado, devido ao aumento da sinuosidade, propriedades localizadas na margem erosiva do rio perderam terreno - e, como constatado em campo, o referido padrão erosivo ameaça inclusive muitas edificações, como pontes e casas. Se as tendências relatadas ao longo do estudo forem mantidas, os impactos serão proporcionais.

A ponderação sobre os condicionantes da morfodinâmica fluvial, portanto, é uma etapa decisiva para a gestão da bacia hidrográfica do rio Cubatão em sua totalidade, já que, segundo Gonçalves et al. (2006), ela é responsável por cerca de $70 \%$ do abastecimento de água de Joinville e de parte do município de Araquari. Questiona-se, assim, a aplicação prática dos pressupostos geomorfológicos no planejamento governamental. Para essa reflexão, considere-se, por exemplo, que o aeroporto de Joinville (um dos maiores do estado de Santa Catarina) foi construído ao lado do rio, no qual a pista de pouso e decolagem inicia-se a menos de 15 metros de distância de uma das margens erosivas do leito natural.

\section{CONCLUSÃO}

A análise multitemporal a partir de fotografias aéreas e imagens de satélite no período que compreende 1938-2015 permitiu identificar as mudanças morfológicas e morfodinâmicas decorrentes da construção da barragem e do canal retificado que dividiu o fluxo do rio Cubatão na década de 1950.

Destaca-se que a eficácia da metodologia é condicionada pela disponibilidade de bases cartográficas históricas, pela adequação de escala (têmporo-espacial) e pelo rigor metodológico em todas as etapas desde $\mathrm{o}$ georreferenciamento das fotografias até as modelagens posteriores. As análises multitemporais viabilizam a compreensão da evolução do processo fluvial sob determinados condicionantes e, assim, podem auxiliar em prognósticos para o planejamento e gestão ambiental. Salienta-se, também, que a análise digital do relevo tem grande potencial de aplicação para estudos mais detalhados, sobretudo na vinculação de dados morfométricos com dados fluviométricos. Outro fator importante a ser considerado nesse tipo de análise é o contexto climático e atmosférico, visto que tanto a sazonalidade quanto os eventos de precipitações ou estiagens severas alteram e tendenciam os resultados. Portanto, a compatibilidade também deve considerar tais características.

Nesse estudo, no primeiro segmento analisado, que contempla o leito natural desde a barragem até o encontro com o canal de derivação, os efeitos observados foram o aumento da sinuosidade $(4,7 \%)$ e a queda progressiva da área ocupada pelo leito de vazante (44\%). Quanto às formas, foi constatada uma significativa remodelagem das barras de pontal, em função do processo de erosão/deposição, enquanto as barras transversais foram reduzidas em 31\% (número de feições), sendo que desse total restante a área das barras teve um decréscimo de $78 \%$.

Para o segundo segmento estudado, desde o encontro do leito natural e canal de derivação até a foz do rio Cubatão, a sinuosidade diminuiu $2 \%$ e a área do leito vazante, de modo destacado, aumentou $16 \%$. Considerando que este é um segmento pouco extenso e próximo à foz, destaca-se a reconfiguração das barras de pontal e, pensando no aporte sedimentar, coloca-se como questionamento os efeitos desse incremento de energia para a baía da Babitonga.

A partir destas constatações conclui-se que, embora o rio seja uma feição muito dinâmica mesmo com predomínio de processos naturais, no baixo curso do rio Cubatão as obras hidráulicas estão induzindo uma reconfiguração morfológica fluvial e acelerando processos evidenciados na paisagem num curto período de tempo.

\section{REFERÊNCIAS}

CHARLTON, R. Fundamentals of fluvial geomorphology. London, Routledge, 2008 https://doi.org/10.4324/9780203371084

CHRISTOFOLETTI, A. Geomorfologia Fluvial. Editora Edigard Blücher, 1981.

CUNHA, S. B. Geomorfologia fluvial. In: GUERRA e GUERRA (Eds.) Geomorfologia: exercícios, técnicas e aplicações. Rio de Janeiro, Bertrand Brasil, 1996. 
GONÇALVES, M. L.; ZANOTELLI, C. T.; OLIVEIRA, F. A. Diagnóstico e prognóstico das disponibilidades e demandas hídricas do Rio Cubatão do Norte - Joinville - Santa Catarina. Joinville, SC: UNIVILLE, 2006.

HAAK, L.; OLIVEIRA, F. A.; POLZIN, M. A. Estudo de dinâmica sedimentar fluvial na bacia hidrográfica do rio Cubatão do Norte - SC. Anais XVI Encontro Nacional de Geógrafos, p. 1-10. Porto Alegre, RS, 2010.

HOOKE, J. M. River meander behaviour and instability: a framework for analysis. Transactions of the Institute of British Geographers 28(2), 238-253, 2003. https://doi.org/10.1111/1475-5661.00089

HOOKE, J. M. Spatial variability, mechanisms and propagation of change in an active meandering river. Geomorphology 84: 277-296, 2007. https://doi.org/10.1016/i.geomorph.2006.06.005

HUTCHINSON, M. F. A new procedure for gridding elevation and stream line data with automatic removal of spurious pits. Journal of Hydrology, 106, p. 211-272, 1989. https://doi.org/10.1016/0022$\underline{1694(89) 90073-5}$

LEWIN, J. Channel pattern changes. In: GREGORY, K.J. (ed.). River channel changes. Wiley, Chichester, p. 167-84, 1977.

LORENZO, R. G.; GARCÍA, C. C.; CUTILLAS, P. P. Análisis espacial de la geometría de meandros abandonados recientes en la Vega Media del Segura (Murcia). In: RIVA, J.; IBARRA, P.; MONTORIO, R.; RODRIGUES, M. (Eds.). Análisis espacial y representación geográfica: innovación y aplicación. Universidad de Zaragoza-AGE, 2015.

MANSIKKANIEMI, H. The sinuosity of rivers in northern Finland: Publicationes Instituti Geographici Universitatis Turkuensis, $52: 16-32,1970$.

MONEGAGLIA, F.; ZOLEZZI, G.; GÜNERALP, I.; HENSHAW, A. J.; TUBINO, M. Automated extraction of meandering river morphodynamics from multitemporal remotely sensed data. Environmental Modelling \& Software, v. 105, p. 171-186, 2018. https://doi.org/10.1016/i.envsoft.2018.03.028

MOSSA, J. The changing geomorphology of the Atchafalaya River, Louisiana: A historical perspective. Geomorphology 252: 112-127, 2016. https://doi.org/10.1016/..geomorph.2015.08.018

OLIVEIRA, F. A. Estudo do aporte sedimentar em suspensão na baía da Babitonga sob a ótica da geomorfologia. Tese de doutorado. Programa de Pós-Graduação em Geografia Física, USP, São Paulo, 2006.

OLIVEIRA, F. A.; VIEIRA, C. V. Semi-detailed Geomorphological Map of Northeastern Santa Catarina State, Brazil-the Garuva Sheet. Journal of Maps, 5:1, 66-74, 2009. https://doi.org/10.4113/jom.2009.1037

PEREIRA, M. E. Compartilhando a gestão dos recursos hídricos: Joinville e o rio Cubatão. Dissertação de Mestrado. Programa de Pós-Graduação em Ciência Ambiental, USP, São Paulo, 2005.

RHOADS, B. L.; LEWIS, Q. W.; ANDRESEN, W. Historical changes in channel network extent and channel planformin an intensively managed landscape: Natural versus human-induced effects. Geomorphology 252: 17-31, 2016. https://doi.org/10.1016/j.geomorph.2015.04.021

ROWLAND, J. C.; SHELEF, E.; POPE, P. A.; MUSS, J.; GANGODAGAMAGE, C.; BRUMBY, S. P.; WILSON, C. J. A morphology independent methodology for quantifying planview river change and characteristics from remotely sensed imagery. Remote Sensing of Environment, n.184, p. 212-228, 2016. https://doi.org/10.1016/j.rse.2016.07.005

SCHWENK, J.; KHANDELWAL, A.; FRATKIN, M.; KUMAR, V.; FOUFOULA-GEORGIOU, E.. High spatio-temporal resolution of river planform dynamics from Landsat: The RivMAP toolbox and results 
from the Ucayali River. Earth and Space Science, v. 4(2), p. 46-75, 2017. https://doi.org/10.1002/2016EA000196

SCORPIO, V.; AUCELLI, P. P. C.; GIANO, S. I.; PISANOA, L.; ROBUSTELLI, G.; ROSSKOPF, C. M.; SCHIATTARELLA, M. River channel adjustments in Southern Italy over the past 150 years and implications for channel recovery. Geomorphology 251, 77-90, 2015. https://doi.org/10.1016/i.geomorph.2015.07.008

SILVEIRA, W. N. Análise histórica de inundação no município de Joinville - SC, com ênfase dabacia do rio Cubatão do Norte. Dissertação de mestrado, Programa de Pós-Graduação em Engenharia Ambiental, UFSC. Florianópolis, 2008.

SURIAN, N.; RINALDI, M. Morphological response to river engineering and management in alluvial $\begin{array}{llll}\text { channels in Italy. Geomorphology } & \text { 50, 307-326, }\end{array}$ https://doi.org/10.1016/S0169-555X(02)00219-2

TARBOTON, D. G. A New Method for the Determination of Flow Directions and Contributing Areas in Grid Digital Elevation Models. Water Resources Research, 33(2): 309-319, 1997. https://doi.org/10.1029/96WR03137

VIEIRA, V. T.; CUNHA, S. B. Mudanças na rede de drenagem urbana de Teresópolis (Rio de Janeiro). In: GUERRA, A. J. T e CUNHA, S. B. (Orgs). Impactos ambientais urbanos no Brasil. Rio de Janeiro: Bertrand Brasil, p. 11-145, 2005.

WINTERBOTTOM, S. J. Medium and short-term channel planform changes on the Rivers Tay and Tummel, Scotland. Geomorphology 34, 195-208, 2000. https://doi.org/10.1016/S0169-555X(00)00007-6

Recebido em: 28/05/2018

Aceito para publicação em: 30/06/2020 